\title{
The relation between gravity rate of change and vertical displacement in previously glaciated \\ areas.
}

\author{
Per-Anders Olsson ${ }^{1,2 *}$, Glenn Milne ${ }^{3}$, Hans-Georg Scherneck ${ }^{2}$, Jonas Ågren ${ }^{1}$
}

Submitted to Journal of Geodynamics

${ }^{1}$ Geodetic Research Division, Lantmäteriet (Swedish mapping, cadastral and land registration authority), SE-801 82 Gävle, Sweden

${ }^{2}$ Onsala Space Observatory, Chalmers University of Technology, SE-439 92 Onsala, Sweden

${ }^{3}$ Department of Earth Science, University of Ottawa, Ottawa ON Canada

*Corresponding author. Telephone: +46 7716363 63, Fax: +46 26610676 ,

E-mail address: per-anders.olsson@lm.se

\begin{abstract}
The rate of change of surface gravity, $\dot{g}$, and vertical deformation rate of the solid surface, $\dot{u}$, are two observables of glacial isostatic adjustment (GIA). They contribute with different information on the same phenomenon. Their relation contain information of the underlying physics and a trustworthy relation allows to combine these observations to strengthen the overall observational accuracy of the phenomenon.

In this paper we investigate the predicted relation between $\dot{g}$ and $\dot{u}$ in previously glaciated areas. We use the normal mode approach for one dimensional earth models and solutions of the sea level equation with time-dependent coastline geometry.

Numerical predictions of $\dot{g}$ and $\dot{u}$ are computed for Laurentia, Fennoscandia and the British Isles respectively, using six different earth models. Within each region a linear trend is then fitted using the relation $\dot{g}=$ $C \dot{u}+\dot{g}_{0}$. The estimated $C$ and $\dot{g}_{0}$ differ more between the regions than between different earth models within each region. For Fennoscandia $C \approx-0.163 \mu \mathrm{Gal} / \mathrm{mm}$ and for Laurentia $C \approx-0.152 \mu \mathrm{Gal} / \mathrm{mm}$. Maximum residuals between the linear trend and spatially varying model predictions of $\dot{g}$ are $0.04 \mu \mathrm{Gal} / \mathrm{yr}$ in Fennoscandia and $0.17 \mu \mathrm{Gal} / \mathrm{yr}$ in Laurentia. For the British Isles the results are harder to interpret, mainly since this region is located on the zero uplift isoline of Fennoscandia.

In addition, we show temporal variation of the relation since the last glacial maximum till present-day.
\end{abstract}


The temporal and spatial variation of the relation between $\dot{g}$ and $\dot{u}$ can be explained by (i) the elastic respectively viscous proportion of the total signal and (ii) the spectral composition of the regional signal.

Additional local effects, such as the Newtonian attraction and elastic deformation from local sea level changes, are examined in a case study for six stations in the Nordic absolute gravity network. The influence of these local effects on the relation between $\dot{g}$ and $\dot{u}$ is negligible except for extreme locations close to the sea.

Keywords: GIA, rate of change of gravity

\section{Introduction}

The ratio between the vertical displacement rate of the solid surface of the Earth, $\dot{u}$, and the rate of change of surface gravity, $\dot{g}$, has been shown to be useful when attempting to separate the present day ice mass (PDIM) change signal from the glacial isostatic adjustment (GIA) signal, the latter induced by historical ice mass variations, in regions like Greenland and Antarctica (Wahr et al., 1995; James and Ivins, 1998; Fang and Hager, 2001; Purcell et al., 2011; Memin et al., 2012). Given that the viscous part of the ratio as well as the elastic part of the ratio (including the direct attraction from surface mass variations) are known, simultaneous observations of $\dot{u}$ (e.g. GPS) and $\dot{g}$ (e.g. repeated absolute gravity observations) can be used to separate the delayed (viscous) signal from the instantaneous (elastic) signal (Memin et al., 2012). This proceeding is motivated by the fact that GIA models for Greenland and Antarctica contain uncertainties due to limited observations constraints (Purcell et al., 2011).

Mainly due to this purpose a number of investigations of the ratio between $\dot{u}$ and $\dot{g}$ have been published. Wahr et al. (1995) found that the viscous part of $\dot{g}$ is approximately proportional to the viscous part of $\dot{u}$ with the constant of proportionality $\sim-0.154 \mu \mathrm{Gal} / \mathrm{mm}\left(1 \mathrm{Gal}=0.01 \mathrm{~m} / \mathrm{s}^{2}\right)$. This approximation was based on empirical tests using a GIA model for Greenland and Antarctica, and was claimed to be insensitive to ice history and viscosity profiles in the mantle, which was later confirmed by Fang and Hager (2001). James and Ivins (1998) predicted $\dot{g}$ and $\dot{u}$ for Antarctica, using the ice model ICE-3G, and found their ratio to be $\sim-0.16 \mu \mathrm{Gal} / \mathrm{mm}$. Purcell et al. (2011) studied the ratio between the viscoelastic load Love numbers $h$ (describing the vertical displacement) and $k$ (describing the gravitational potential change) in the spectral domain. This ratio depends on the harmonic degree and was here determined empirically from modelling.

In Laurentia in North America and Fennoscandia in northern Europe the situation is different. These regions were covered with ice during the Late Pleistocene but are long since ice free. Here the signal is a pure GIA signal (neglecting the small elastic response from sea level variations). 
Table 1: Published observations of $\dot{g} / \dot{u}$ in previously glaciated areas.

\begin{tabular}{|c|c|c|c|}
\hline Area & $\begin{array}{l}\dot{g} / \dot{u} \\
{[\mu G a l / m m]}\end{array}$ & Note & Reference \\
\hline Fenno. & $-0.204 \pm 0.058^{1}$ & $\begin{array}{l}\text { Relative gravity observations } \\
\text { every 5th year; time span } \sim \\
27 \text { years. } \dot{u} \text { from mareographs } \\
\text { and levelling. }\end{array}$ & Ekman and Mäkinen (1996) \\
\hline Fenno. & $\begin{array}{l}-0.16 \pm 0.05 \text { to } \\
-0.18 \pm 0.06^{1}\end{array}$ & $\begin{array}{l}\text { Ekman and Mäkinen (1996) } \\
\text { revisited, now with more ob- } \\
\text { servations. The different esti- } \\
\text { mations of the ratio is related } \\
\text { to different estimations of } \dot{u} \\
\text { (now including GPS). }\end{array}$ & Mäkinen et al. (2005) \\
\hline Fenno. & $-0.163 \pm 0.02^{2}$ & $\begin{array}{l}\text { Four years of annual AG- } \\
\text { observations on eight sta- } \\
\text { tions. } \dot{u} \text { from GPS Lidberg } \\
\text { et al. ( } 2007) \text {. For the differ- } \\
\text { ent stations the ratio varies } \\
\text { between }-0.114 \pm 0.031 \text { and } \\
-0.232 \pm 0.059 .\end{array}$ & Gitlein (2009) \\
\hline Fenno. & -0.17 to -0.22 & $\begin{array}{l}13 \text { stations with repeated } \\
\text { AG observations compared to } \\
\text { tide gauges data and GPS ve- } \\
\text { locities }\end{array}$ & Pettersen (2011) \\
\hline Laurentia & $\sim-0.154$ & $\begin{array}{l}\text { Four stations of co-located } \\
\text { GPS and AG. Total time span } \\
6 \text { years. Number of AG obser- } \\
\text { vations at the stations were } 2 \text {, } \\
2,5 \text {, many. The ratio }-0.154 \text {, } \\
\text { from Wahr et al. ( } 1995) \text {, is } \\
\text { within the error bars of these } \\
\text { observations. }\end{array}$ & Larson and van Dam (2000) \\
\hline Laurentia & $-0.18 \pm 0.03^{2}$ & $\begin{array}{l}\text { Four stations of co-located } \\
\text { GPS and AG. Three of the } \\
\text { stations are the same as in } \\
\text { Larson and van Dam (2000). } \\
\text { Annual (at least) measure- } \\
\text { ments in a time span of } \sim 8 \\
\text { years. }\end{array}$ & Lambert et al. (2006) \\
\hline Laurentia & $-0.17 \pm 0.01^{2}$ & $\begin{array}{l}\text { Eight AG stations whereof six } \\
\text { are co-located with GPS, in- } \\
\text { cluding the four stations in } \\
\text { Lambert et al. (2006). Time } \\
\text { spans } 7-21 \text { years. }\end{array}$ & Mazzotti et al. (2011) \\
\hline
\end{tabular}


Fennoscandia has a long history of GIA observations in terms of e.g. sea level observations and levelling campaigns (Ekman, 1996), and during the last decades a lot of effort has been put in establishing a dense network of permanent GNSS stations (Scherneck et al., 2002) and co-located absolute gravity (AG) stations (Gitlein, 2009) in this region. Also in Laurentia a number of co-located GNSS and AG stations have been established (Mazzotti et al., 2011). One of the main long time goals of these efforts is to perform accurate observations of $\dot{u}$ and $\dot{g}$. Table 1 summarizes some published studies of the observed ratio $\dot{g} / \dot{u}$ in these regions.

As the time series of continuous GNSS observations of $\dot{u}$ and repeated AG observations of $\dot{g}$ get longer and the observational accuracy increases, the question of their relation becomes prominent. Is a simple ratio accurate for relating geodetic observations of $\dot{g}$ and $\dot{u}$ in previously glaciated areas?

The purpose of this paper is to investigate, via a modelling analysis, how robust a single relation between $\dot{u}$ and $\dot{g}$ is in previously glaciated areas, like Laurentia and Fennoscandia. Given a certain GIA model (described in Section 2 ) we predict $\dot{u}$ and $\dot{g}$ and show how their relation varies within each region and between the regions (Section 3). We also show, numerically, how it varies for different viscosity profiles in the earth model and how it varies in time since last glacial maximum (LGM) till present-day. Furthermore we investigate if additional effects from present-day sea level variations, like elastic deformation and direct attraction from the water masses, can be expected to affect the relation significantly (Section 4). Finally, we summarize the main findings in Section 5.

\section{GIA-model}

In Sections 3 and 4 a GIA-model is used to make predictions of $\dot{g}$ and $\dot{u}$. In this section the modelling method is indicated with references to more detailed descriptions, and relevant modelling parameters are presented. We also show some characteristics of the model since these will show important for the interpretation of the results in Sections 3 and 4.

The method used in the GIA-modelling is the normal mode approach for a one dimensional, laterally homogenous, spherical Maxwell Earth (Peltier, 1974; Cathles, 1975; Peltier and Andrews, 1976; Peltier, 1976; Wu, 1978; Wu and Peltier, 1982, 1983; Peltier, 1985). Specifically, our solution to the impulse response of a viscoelastic earth is expanded with the so-called collocation method, an approximation to the normal mode method proper. A critical evaluation of the two methods is found in Mitrovica and Peltier (1992).

Based on the Preliminary Reference Earth Model (PREM) (Dziewonski and Anderson, 1981) viscoelastic load Love numbers (degree 1-180) have been computed using six different sets of earth model parameters (see Table 2). The digits in the model names represent lithospheric thickness $[\mathrm{km}]$, upper mantle viscosity $\left[10^{21} \mathrm{~Pa} \mathrm{~s}\right]$ and lower mantle viscosity $\left[10^{21} \mathrm{~Pa} \mathrm{~s}\right]$, respectively. The $96 \_0.5 \_10$ compressible model is assumed to represent a realistic global aver- 
age. The other models have been chosen so that the values for upper mantle viscosity and lithospheric thickness span a relatively broad range of values. We also considered a model that is identical to our reference model (96_0.5_10) except for that the elastic Lamé parameter was set very high to mimic the incompressible case. The ice load history is defined by the ICE-5G model (Peltier,

Table 2: Earth model parameters. The upper mantle is defined from the bottom of the lithosphere to $670 \mathrm{~km}$ depth. The viscosity in the lower mantle (from 670 $\mathrm{km}$ to the top of the fluid core) is $10^{22} \mathrm{~Pa}$ s for all models.

\begin{tabular}{lcccc}
\hline \hline $\begin{array}{l}\text { Model } \\
\text { name }\end{array}$ & Comp. & Incomp. & $\begin{array}{c}\text { Lithospheric } \\
\text { thickness }[\mathrm{km}]\end{array}$ & $\begin{array}{c}\text { Upper mantle } \\
\text { viscosity }\left[10^{21} \mathrm{~Pa} \mathrm{~s}\right]\end{array}$ \\
\hline $96 \_0.5 \_10$ & yes & & 96 & 0.5 \\
$96 \_0.5 \_10 \_$incomp & & yes & 96 & 0.5 \\
$96 \_0.1 \_10$ & yes & & 96 & 0.1 \\
$96 \_1 \_10$ & yes & & 96 & 1 \\
$71 \_0.5 \_10$ & yes & & 71 & 0.5 \\
$120 \_0.5 \_10$ & yes & & 120 & 0.5 \\
\hline
\end{tabular}

2004) as included in the software SELEN 2.7 (Spada, 2003), i.e. 1 kyr time steps starting at the last glacial maximum (LGM) $21 \mathrm{kyr}$ before present.

The response of the sea to the ice load changes has been computed by solving the Sea Level Equation (SLE) (Farrell and Clark, 1976) with time-dependent coastline geometry following Mitrovica and Milne (2003) and Kendall et al. (2005). A more thorough description of our SLE solution can be found in Olsson et al. (2012).

With this definition of the GIA-model, the Earth's response to surface load variations is given. In order to understand the relation between $\dot{g}$ and $\dot{u}$, and how it varies in time and space, we will now examine some of the characteristics of the model.

Figure 1 illustrates how the load Love numbers for earth model 96_0.5_10 depend on the spherical harmonic degree and time. In order to make this plot relevant for $\dot{u}$ and $\dot{g}$ it shows the time derivative after convolution over a Heaviside step function representing the unloading of a unit point mass from the surface. Love number $\dot{h}_{n}(t)$ describes the vertical motion rate of the crust and

$$
\dot{\delta}_{n}(t)=-2 \dot{h}_{n}(t)+(n+1) \dot{k}_{n}(t),
$$

the rate of change of surface gravity (Longman, 1963). Love number $\dot{k}_{n}$ is related to the redistribution of masses within the Earth. The ratio $\dot{\delta}_{n}(t) / \dot{h}_{n}(t)$ scaled by $g_{E} / a$, where $g_{E}$ is the normal gravity and $a$ is the radius of the Earth, is also plotted. This is $\dot{g} / \dot{u}$ in the spectral domain. The time dependence is illustrated at two different times, 1 and $10 \mathrm{kyrs}$ after the unloading. It is clear that both $\dot{h}_{n}$ and $\dot{\delta}_{n}$ decrease with time but that their ratio is rather constant in time. The ratio is dependent on the spherical harmonic degree however. Figure 


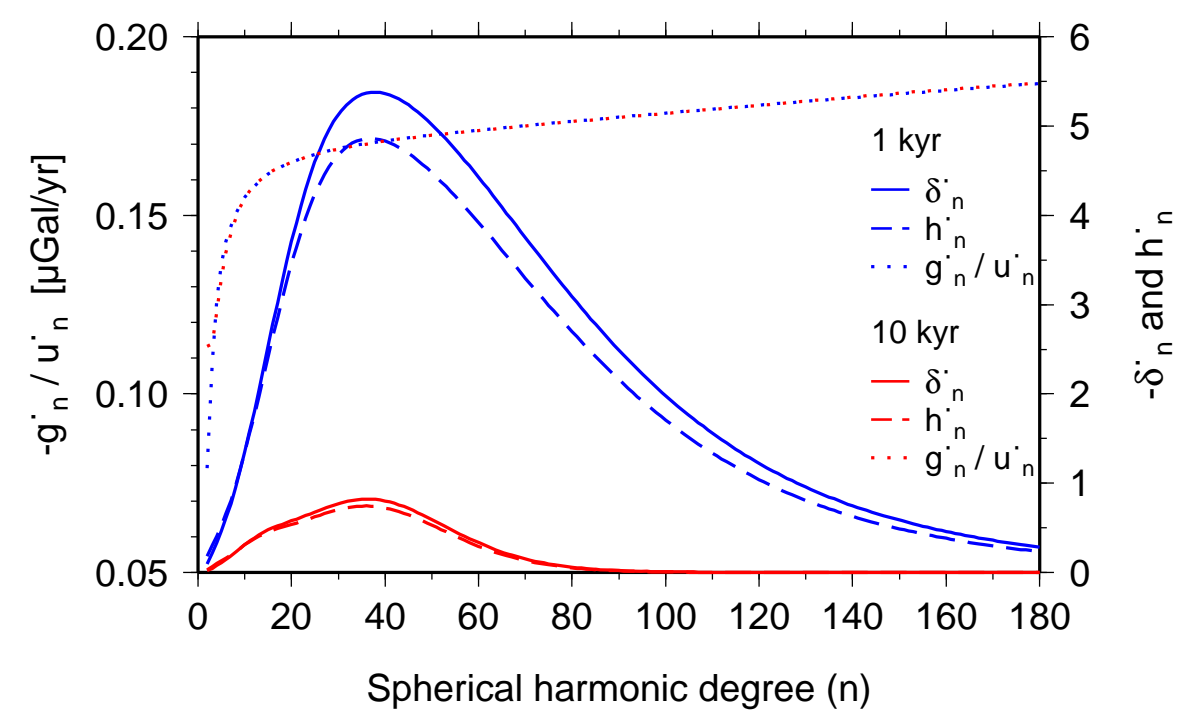

Figure 1: $\dot{\delta}_{n}$ (solid line), $\dot{h}_{n}$ (dashed line), and their ratio scaled by $g_{E} / a$ (dotted line), 1 respectively $10 \mathrm{kyrs}$ after Heaviside unloading of a unit point mass. Earth model: 96_0.5_10 (see Table 2).

2 illustrates how

$$
\begin{aligned}
& \dot{\delta}(\theta, t)=\sum_{n=1}^{180}\left[-2 \dot{h}_{n}(t)+(n+1) \dot{k}_{n}(t)\right] P_{n}(\cos \theta) \quad \text { and } \\
& \dot{h}(\theta, t)=\sum_{n=1}^{180} \dot{h}_{n}(t) P_{n}(\cos \theta)
\end{aligned}
$$

depend on the spherical distance $\theta$ between the point of observation and the load point. $\dot{\delta}(\theta, t)$ and $\dot{h}(\theta, t)$ are the Green's functions for gravity and vertical displacement respectively, which convolved over the ice model in time and space give

$$
\begin{aligned}
& \dot{g}=\frac{G}{a^{2}} \sum_{i=1}^{N} \sum_{j=1}^{M} I_{i j} \dot{\delta}\left(\theta_{i}, t_{j}\right), \\
& \dot{u}=\frac{a}{m_{E}} \sum_{i=1}^{N} \sum_{j=1}^{M} I_{i j} \dot{h}\left(\theta_{i}, t_{j}\right),
\end{aligned}
$$

where $G, a$ and $m_{E}$ are the gravitational constant, radius and mass of the Earth respectively, $N$ and $M$ are the number of pixels and time steps in the ice model, $I_{i j}$ is the load (mass) at pixel $i$ and time step $j, \theta_{i}$ the distance between load pixel $i$ and the point of observation and $t_{j}$ is the timespan between presentday and time step $j$. From Figure 2 it is clear that not only $\dot{\delta}(\theta)$ and $\dot{h}(\theta)$ 
depend on the distance from the loading event, but also their ratio. Close to the loading point, the signal is dominated by shorter wavelengths which imply a higher absolute value of the ratio (see Figure 1). When $\theta$ is close to zero the ratio reaches its maximum, $\sim-0.17 \mu \mathrm{Gal} / \mathrm{mm}$, which is close to the Bouguer approximation discussed in e.g. Ekman and Mäkinen (1996) and James and Ivins (1998). Further away from the loading point (increasing $\theta$ ) the absolute value of ratio decreases and eventually reaches minus infinity as $\dot{h}(\theta)$ goes to 0 (see also discussion in conjunction with Figures 4 and 5 ). It is also clear that this ratio, $\dot{g} / \dot{u}$, contrary to $\dot{g}_{n} / \dot{u}_{n}$ (Figure 1 ), depends on time.

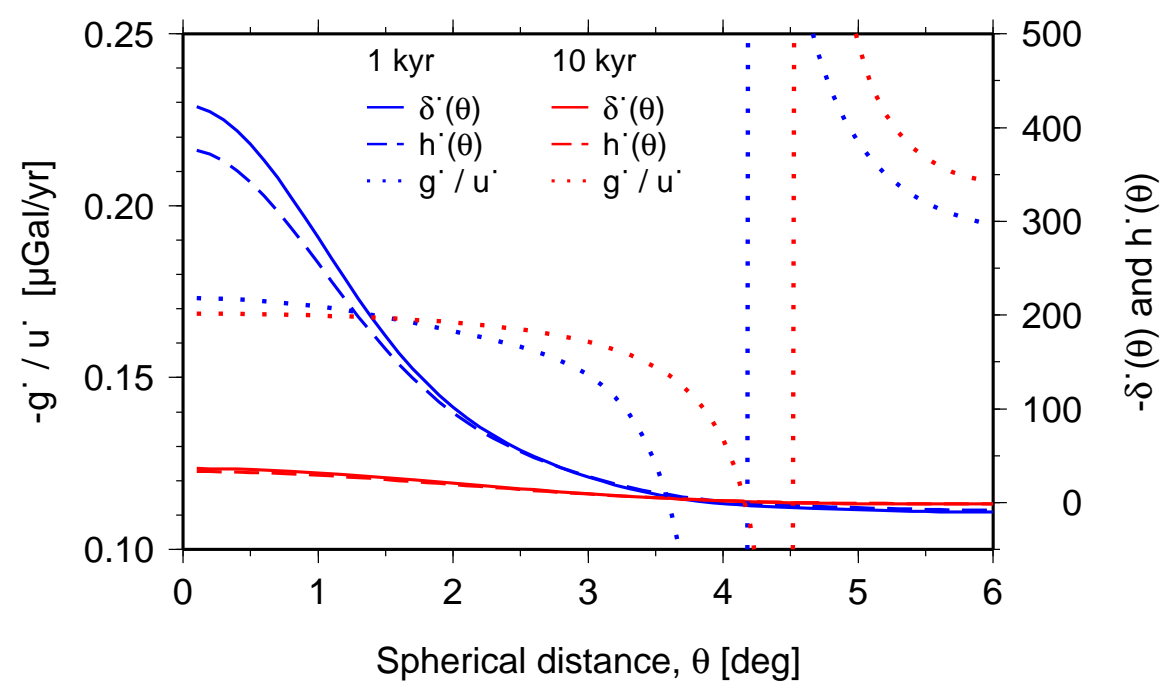

Figure 2: $\dot{\delta}(\theta)$ (solid line), $\dot{h}(\theta)$ (dashed line), and their ratio scaled by $g_{e} / a$ ( dotted line), 1 respectively 10 kyrs after Heaviside unloading of a unit point mass. Earth model: $96 \_0.5 \_10$ (see Table 2).

With these characteristics of the GIA-model in mind we are now ready to examine implemented modelling.

\section{Regional studies of the relation between $\dot{g}$ and $\dot{u}$}

\subsection{Pre-requisites}

In this section we make numerical predictions of the relation between modelled $\dot{g}$ and $\dot{u}$ in three different regions: (i) Laurentia in North America, (ii) Fennoscandia in northern Europe and (iii) Great Britain and Ireland in western Europe. Common for these three regions is that they were covered with ice during the 
last glacial maximum and that they are now ice-free. This implies that, except for a small elastic signal from the relatively small present GIA-induced ocean load changes, the GIA signal today is a purely viscous signal, a result of the previous ice load history. The regions differ in the sense that the extent and thickness of the ice sheets were different, largest in Laurentia and smallest over Great Britain and Ireland. Figure 3 shows the present-day rebound pattern in these three regions, here visualized by predictions of $\dot{g}$ using the GIA model described in Section 2.

A viscoelastic Maxwell Earth responds to surface load changes with two parts, one instantaneous (elastic) and one delayed (viscous). When studying the relation between $\dot{g}$ and $\dot{u}$ it is meaningful to separate the signals into their elastic and viscous parts such that

$$
\begin{aligned}
& \dot{u}=\dot{u}^{e}+\dot{u}^{v}, \\
& \dot{g}=\dot{g}^{N}+\dot{g}^{e}+\dot{g}^{v},
\end{aligned}
$$

where $\dot{g}^{N}$ is the Newtonian or direct attraction of the surface loads themselves (known as the direct effect). It is well known that the viscous ratio $\dot{g}^{v} / \dot{u}^{v}$ is not the same as the elastic ratio $\dot{g}^{e} / \dot{u}^{e}$ (see e.g. Memin et al., 2012). The viscous ratio is generally assumed to be $\sim-0.15$ to $-0.16 \mu \mathrm{Gal} / \mathrm{mm}$ (Wahr et al., 1995; Fang and Hager, 2001; Purcell et al., 2011) and the elastic ratio $\sim-0.21$ to $-0.24 \mu \mathrm{Gal} / \mathrm{mm}$, depending on e.g. the compressibility of the Earth (de Linage et al., 2007).

The direct attraction from the surface loads $g^{N}$ is very sensitive to load changes near the point of observation. In the de-glaciated regions of this study, the only existing GIA-induced surface mass load variations are sea level variations. Water masses located further away than about $10 \cdot H$ (where $H$ is the height above sea level) from the point of observation make little contribution to direct attraction (Olsson et al., 2009). On the other hand, water masses within this radius might have a significant impact on the total gravity change. The direct attraction from nearby water masses is also strongly dependent on the local topography and geometry of the coastline. Correct modelling of this signal requires rigorous treatment of the local conditions and it is therefore, and because of its very local nature, not included in the regional averages computed in this section. In Section 4 the additional local influence of $g^{N}$ is studied in detail for a selection of stations in the Nordic AG-network.

It should also be noted that with $\dot{g}$ we mean the rate of change of surface gravity which can be observed by a superconducting gravimeter or by repeated observations with an absolute gravimeter. It consists, aside from the direct attraction, of one part caused by the vertical movement of the instrument, $\dot{g}_{u}$, and one part caused by the redistribution of masses within the Earth, $\dot{g}_{m}$ such that

$$
\begin{array}{ll}
\dot{g}^{e}= & \dot{g}_{u}^{e}+\dot{g}_{m}^{e} \\
\dot{g}^{v}= & \dot{g}_{u}^{v}+\dot{g}_{m}^{v} .
\end{array}
$$




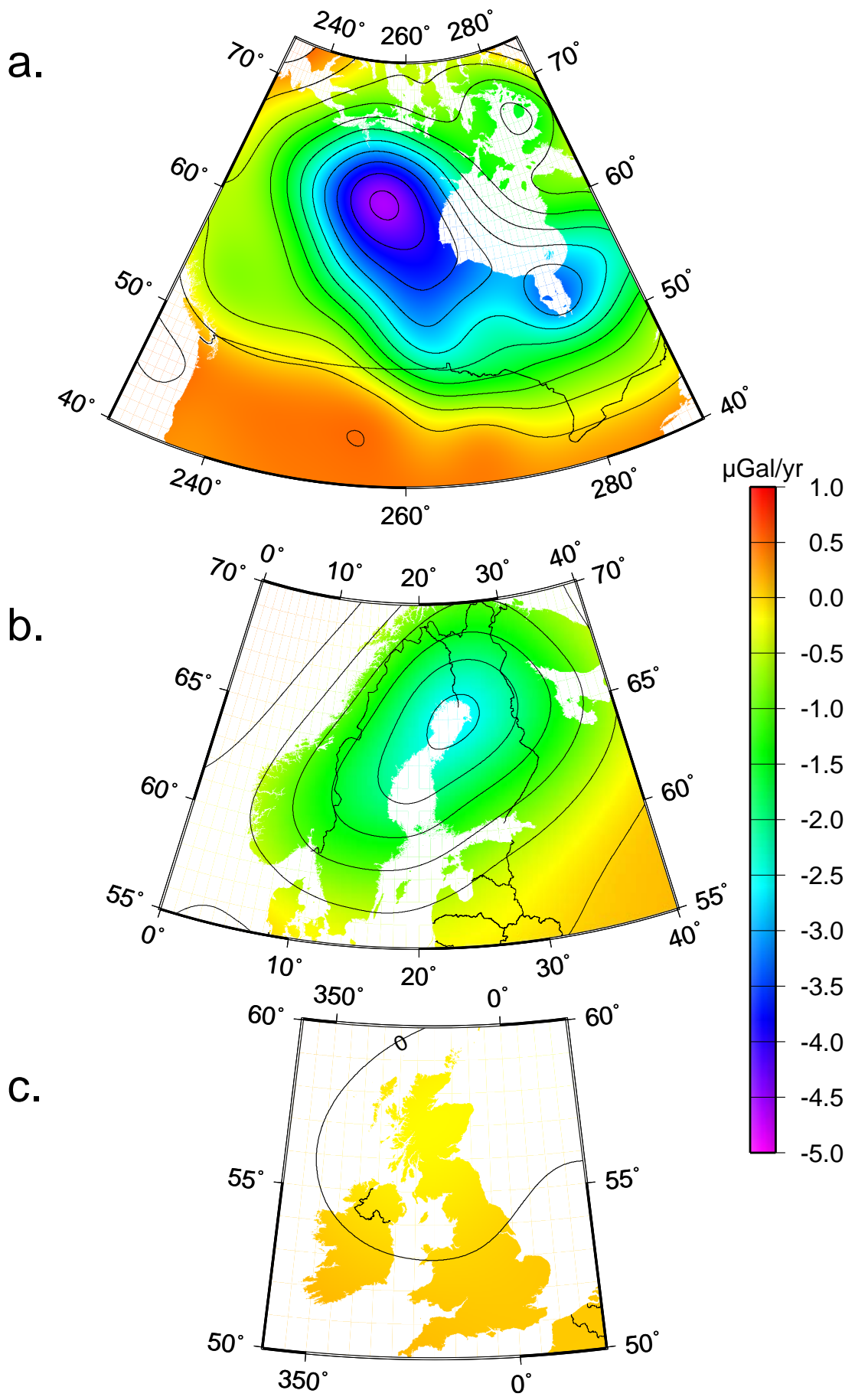

Figure 3: Predictions of $\dot{g}$ (without direct attraction from sea level variations) for (a) Laurentia, (b) Fennoscandia and (c) the British Isles. Earth model 96_0.5_10 (see Table 2). 


\subsection{Regional results}

We start by looking at the ratio $\dot{g}^{e+v} / \dot{u}$, where $\dot{g}^{e+v}=\dot{g}^{e}+\dot{g}^{v}$. The direct attraction term is not included for reasons discussed above. $\dot{g}^{e+v}$ and $\dot{u}$ have been predicted, with the GIA model described in Section 2, for points in a $0.1 \times 0.1$ degree grid over Fennoscandia (lat/long limits as in Figure 3b). The ratio is plotted in Figure 4. As we move away from the uplift center the absolute value of the ratio decrease - more rapidly as we approach the limit of the land uplift area. The reason for this behaviour can be found in Figure 5 where $\dot{g}^{e+v}$ is plotted as a function of $\dot{u}$ together with the linear regression trend

$$
\dot{g}^{e+v}=C \dot{u}+\dot{g}_{0} .
$$

Here we see that $\dot{g}^{e+v}$ approaches zero before $\dot{u}$ (moving from the uplift center towards the zero line). This means that the ratio will decrease and become zero when $\dot{g}^{e+v}$ is zero, then change sign and go to infinity as $\dot{u}$ becomes zero, change sign again and then decreases from infinity to more realistic values (cf. Figure 2). This makes plots like Figure 4 hard to interpret and we choose to quantify the relation between $\dot{g}^{e+v}$ and $\dot{u}$ with the constants $C$ and $\dot{g}_{0}$ in Eq. (7) achieved by fitting a linear trend to the GIA model predictions.

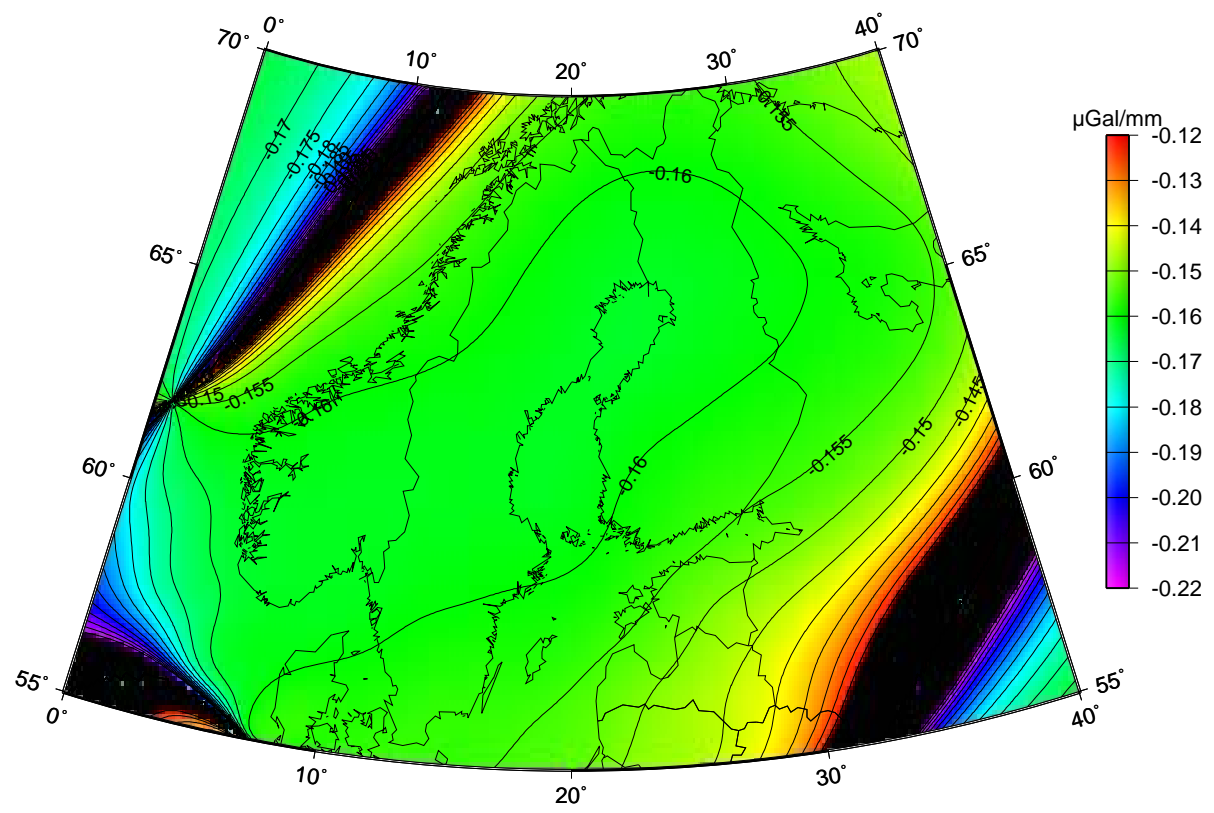

Figure 4: $\dot{g}^{e+v} / \dot{u}$ in Fennoscandia. Values greater than -0.12 or less -0.22 have been blanked with black colour. Earth model 96_0.5_10 (see Section 2).

On land the parameter is almost completely determined from viscosity; however, as we approach the sea the contribution from elasticity increases (see Figure 


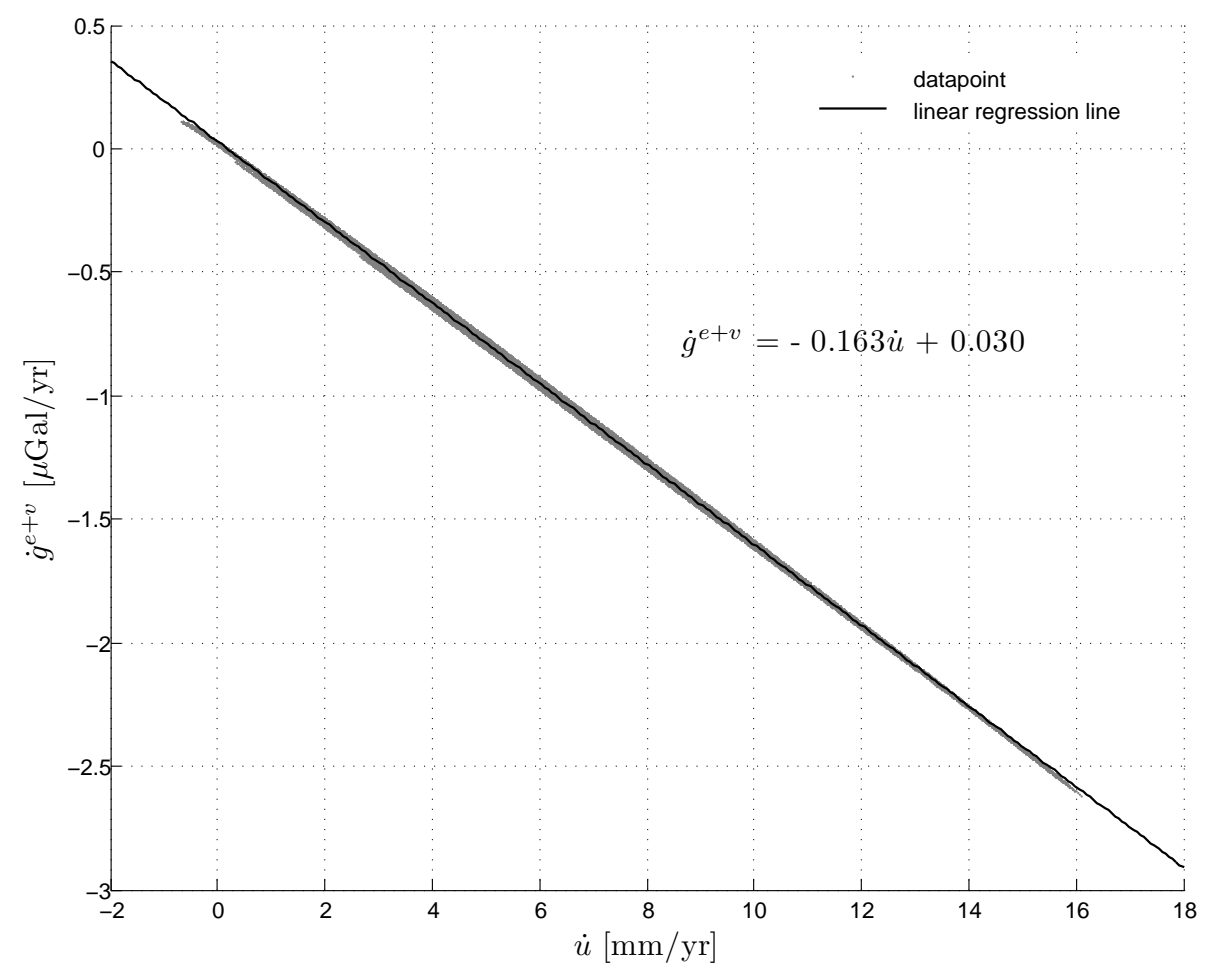

Figure 5: Linear regression line for the relation between $\dot{g}^{e+v}$ and $\dot{u}$ in $58 \%$ of the data points in Fennoscandia. Points in the ocean have been excluded (see text). Earth model: $96 \_0.5 \_10$ (see Table 2 ).

8). Since we are not able to measure surface gravity change on or below the sea surface, we restrict the domain for the trend estimation to land points only.

In Eq. (7) we assume that the relation between $\dot{g}^{e+v}$ and $\dot{u}$ is linear. In order to study deviations from this approximation we look at the residuals $\epsilon$

$$
\dot{g}^{e+v}=C \dot{u}+\dot{g}_{0}+\epsilon
$$

Figure $6 \mathrm{~b}$ shows how $\epsilon$ varies over Fennoscandia, i.e. how well the assumption of a linear relation between $\dot{g}^{e+v}$ and $\dot{u}$ holds for the GIA model in question. Figure 6 a and $6 \mathrm{c}$ shows how $\epsilon$ varies over Laurentia and the British Isles respectively. $C$ and $\dot{g}_{0}$ have been found by linear regression in the same way as for Fennoscandia (see Table 3).

By comparing Figure 3a and 3b with Figure 6a and 6b, respectively, it can be seen that at the different uplift centres and outside the area of uplift (on the peripheral forebulge) the absolute value of $\dot{g}$ is underestimated by the linear relation compared to the full model. This can be explained as follows: (i) Within the uplift area $\dot{g}$ is negative and $\dot{u}$ is positive. From Figure 2 and Eq. (4) follows that, at the uplift centres, located close to where the ice thickness was greatest, 


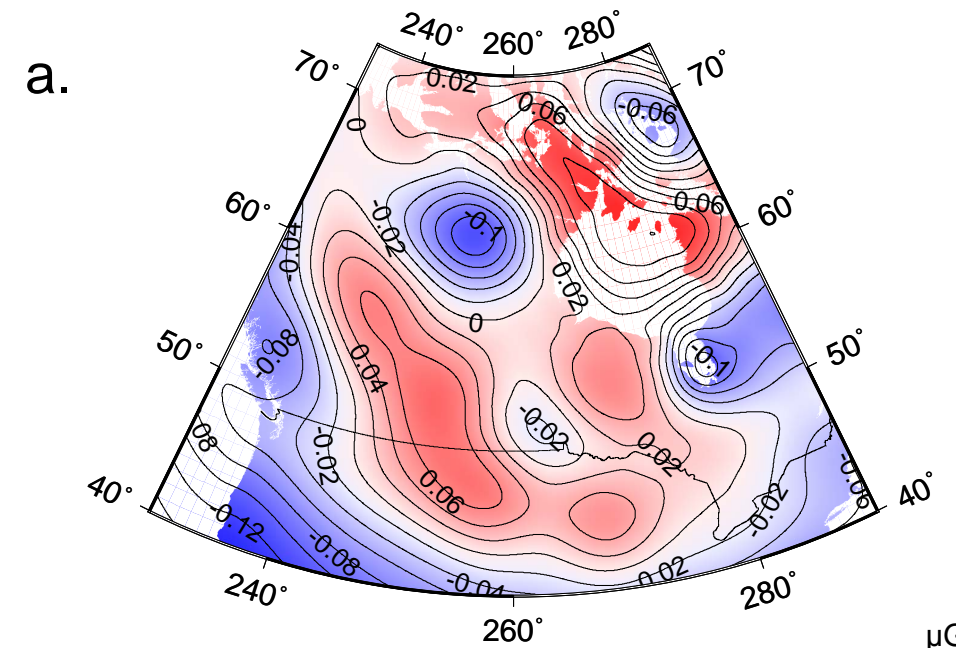

b.

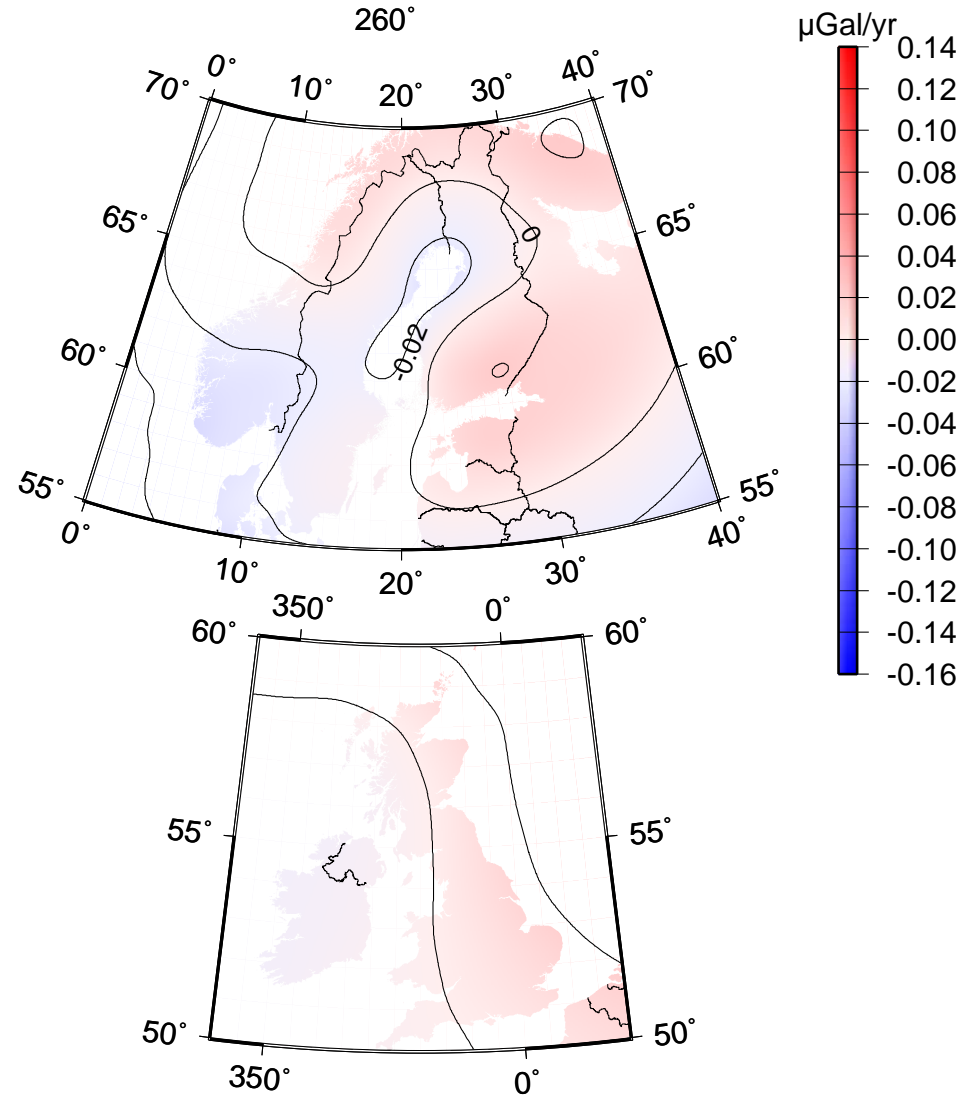

Figure 6: $\epsilon=\dot{g}-C \dot{u}-\dot{g}_{0}$ for (a) Laurentia $\left(C=0.152, \dot{g}_{0}=-0.121\right)$, (b) Fennoscandia $\left(C=0.163, \dot{g}_{0}=-0.030\right)$ and $(\mathrm{c})$ Great Britain and Ireland $\left(C=0.160, \dot{g}_{0}=0.047\right)$. Earth model: $96 \_0.5 \_10$ (see Table 2$)$. 
the coefficients $I_{i j}$ in Eq. (4) will be large for small $\theta_{i}$, and $\dot{g}$ and $\dot{u}$ will be dominated by contributions from small $\theta_{i}$. Figure 2 indicates that for small $\theta$ the absolute value of the ratio tends to higher values, that is, higher than the average, $C$. Using $C$ to estimate $\dot{g}$ here, imply a less negative value compared to $\dot{g}$ predicted with the GIA model, and $\epsilon$ is negative. (ii) On the peripheral forebulge the situation is opposite; $\dot{g}$ is positive and $\dot{u}$ is negative; estimates of $\dot{g}$ using the linear relation (here dominated by $\dot{g}_{0}$ since $\dot{g}$ and $\dot{u}$ are close to zero) will be too high compared to $\dot{g}$ predicted with the GIA-model, and $\epsilon$ become negative.

Table 3 summarizes $C, \dot{g}_{0}, \epsilon_{\max }, \epsilon_{\min }$ and $\sigma_{\epsilon}$ (the standard deviation of $\epsilon)$ computed with the six earth models described in Section 2 for the three regions in Figure 3. For Fennoscandia and Laurentia, the relation between $\dot{g}$ and $\dot{u}$ differs less between earth models within one region than between regions. In Laurentia the absolute value of the ratio is lower than in Fennoscandia. The difference is due to the different spectral composition of the loads in these regions. The larger ice sheet in Laurentia implies that the rebound signal is stronger in the lower part of the spectrum resulting in a lower ratio (Figure 1). Two of the earth models stand out with low ratios in both Laurentia and Fennoscandia. Both of them are less realistic than the others. The earth model 96_0.5_10_incomp has incompressible rheology and the model 96_0.1_10 has unrealistically low viscosity in the upper mantle. This low viscosity makes the whole relaxation process faster, with the result that at present-day there is almost no GIA-signal left; in Fennoscandia $\dot{u}_{\max } \approx 1 \mathrm{~mm} / \mathrm{yr}$ for this model compared to the more realistic value $\dot{u}_{\max } \approx 10 \mathrm{~mm} / \mathrm{yr}$. Less signal left, means a smoother signature, a shift towards longer wavelengths and a lower ratio. Neglecting these two (less realistic) earth models allow us to claim that $C \approx$ $-0.163 \mu \mathrm{Gal} / \mathrm{mm}$ in Fennoscandia and $C \approx-0.152 \mu \mathrm{Gal} / \mathrm{mm}$ in Laurentia. It is harder to make any conclusions on the relation in Great Britain and Ireland. This is due to the fact that here the rebound signal is very small (see Figure 3 ), which makes the ratio very sensitive to small variations in $\dot{g}$ and $\dot{u}$. The fact that $\dot{g}_{0} \neq 0$ implies that $C$ is not exactly $\dot{g} / \dot{u}$. The difference increases as $\dot{u} \rightarrow 0$. When $\dot{u}=0$ then $\dot{g}=\dot{g}_{0}$.

The observed ratios in Table 1 are based on linear regression lines fitted to observations at different locations within the region in question. They represent therefore regional averages corresponding approximately to $C$. The error estimates given in this Table 1 indicate, without deeper examination, that the accuracy of observations of $\dot{g}$ and $\dot{u}$ are still too low to confirm (or reject) the modelled difference of $C$ between e.g. Fennoscandia and Laurentia.

For the purpose of comparing or combining geodetic observations of $\dot{g}$ and $\dot{u}$, the error you make using a simple ratio is more interesting than the ratio itself. Within our adopted GIA-model this corresponds to the residuals $\epsilon$. In Fennoscandia $-0.04<\epsilon<0.04$ and in Laurentia $-0.17<\epsilon<0.15$ [ $\mu \mathrm{Gal} / \mathrm{yr}]$ (Table 3 and Figure 6). This can be compared to an expected observational accuracy $0.1 \mu \mathrm{Gal} / \mathrm{yr}$ from $15-25 \mathrm{yrs}$ of annual or semiannual AG observations (Van Camp et al., 2005). In Fennoscandia $\epsilon$ is relatively small compared to the expected observational accuracy but in Laurentia the spatial variations of $\epsilon$ 
Table 3: $C$ and $\dot{g}_{0}$ (Eq. 7) from linear regression of modelled $\dot{g}^{e+v}$ and $\dot{u}$ (c.f. Figure 5). $\epsilon$ according to Eq. (8). $0.2 \times 0.2$ degree grid in Laurentia and $0.1 \times 0.1$ degree grids in Fennoscandia and the British Isles. Lat/long limits as in Figure 3. Points in the ocean excluded.

\begin{tabular}{|c|c|c|c|c|c|}
\hline Model & $\begin{array}{c}C \\
{[\mu \mathrm{Gal} / \mathrm{mm}]}\end{array}$ & $\begin{array}{c}\dot{g}_{0} \\
{[\mu \mathrm{Gal} / \mathrm{yr}]}\end{array}$ & $\begin{array}{c}\epsilon_{\max } \\
{[\mu \mathrm{Gal} / \mathrm{yr}]}\end{array}$ & $\begin{array}{c}\epsilon_{\min } \\
{[\mu \mathrm{Gal} / \mathrm{yr}]}\end{array}$ & $\begin{array}{c}\sigma_{\epsilon} \\
{[\mu \mathrm{Gal} / \mathrm{yr}]}\end{array}$ \\
\hline \multicolumn{6}{|l|}{ Laurentia } \\
\hline $96 \_0.5 \_10$ & -0.1521 & 0.1211 & 0.1199 & -0.1360 & 0.0472 \\
\hline 96_0.5_10_incomp & -0.1486 & 0.0875 & 0.1234 & -0.1213 & 0.0418 \\
\hline 96_0.1_10- & -0.1484 & 0.0309 & 0.0172 & -0.0715 & 0.0086 \\
\hline $96 \_1 \_-\overline{10}$ & -0.1521 & 0.1471 & 0.1526 & -0.1708 & 0.0657 \\
\hline $71-0 . \overline{5} \_10$ & -0.1525 & 0.1195 & 0.1357 & -0.1364 & 0.0517 \\
\hline $120 \_0 . \overline{5} \_10$ & -0.1518 & 0.1222 & 0.1161 & -0.1350 & 0.0431 \\
\hline \multicolumn{6}{|l|}{ Fennoscandia } \\
\hline $96 \quad 0.5 \quad 10$ & -0.1633 & 0.0298 & 0.0225 & -0.0313 & 0.0129 \\
\hline $96 \quad 0.5-10$ incomp & -0.1597 & 0.0226 & 0.0190 & -0.0317 & 0.0115 \\
\hline $96 \_0.1 \_10$ & -0.1552 & -0.0252 & 0.0115 & -0.0116 & 0.0050 \\
\hline $96 \_1 \_10$ & -0.1634 & 0.0372 & 0.0365 & -0.0398 & 0.0163 \\
\hline $71 \_0.5 \_10$ & -0.1637 & 0.0279 & 0.0286 & -0.0318 & 0.0145 \\
\hline $120 \_0.5 \_10$ & -0.1627 & 0.0300 & 0.0176 & -0.0313 & 0.0114 \\
\hline \multicolumn{6}{|l|}{ British Isles } \\
\hline $96 \_0.5 \_10$ & -0.1597 & -0.0466 & 0.0255 & -0.0143 & 0.0082 \\
\hline 96_0.5_10_incomp & -0.1545 & -0.0533 & 0.0218 & -0.0164 & 0.0090 \\
\hline $96 \_0.1 \_10$ & -0.1496 & -0.0382 & 0.0054 & -0.0014 & 0.0011 \\
\hline $96 \_1 \_10$ & -0.1655 & -0.0532 & 0.0326 & -0.0198 & 0.0096 \\
\hline $71 \_0.5 \_10$ & -0.1632 & -0.0491 & 0.0234 & -0.0149 & 0.0079 \\
\hline $120 \_0.5 \_10$ & -0.1519 & -0.0414 & 0.0211 & -0.0125 & 0.0080 \\
\hline
\end{tabular}

should be recognized as the time-series of AG-observations get longer and the ratio is exerted.

\subsection{Time dependence}

In this section the time evolution of the relation between $\dot{g}$ and $\dot{u}$ since LGM is studied, it adds useful information to better understand the processes that control this relation and since this period includes the melting phase of the ice sheets it can also be used to make parallels to areas with PDIM changes.

Figure 7 shows the evolution of $C$ in Fennoscandia (Eq. 7) as a function of time. $C$ has been found by linear regression, as described above, for each time step since LGM, $21 \mathrm{kyr}$ BP, till present. All grid points in the area are used. The direct attraction term, $g_{N}$, is not included. During the first 10 kyrs the majority of the area considered was covered with melting ice, which means that in each time step there is a considerable elastic signal directly connected to the decreasing load. The elastic ratio, found from linear regression between $\dot{g}^{e}$ and 
$\dot{u}^{e}$, as well the viscous ratio, from $\dot{g}^{v}$ and $\dot{u}^{v}$ are plotted explicitly. The time evolution of the total signal depends on the relative proportion of elastic versus viscous contributions. From 8 kyrs BP the ice has melted in the whole region and except for the viscous signal there is only the small elastic signal from sea level changes.

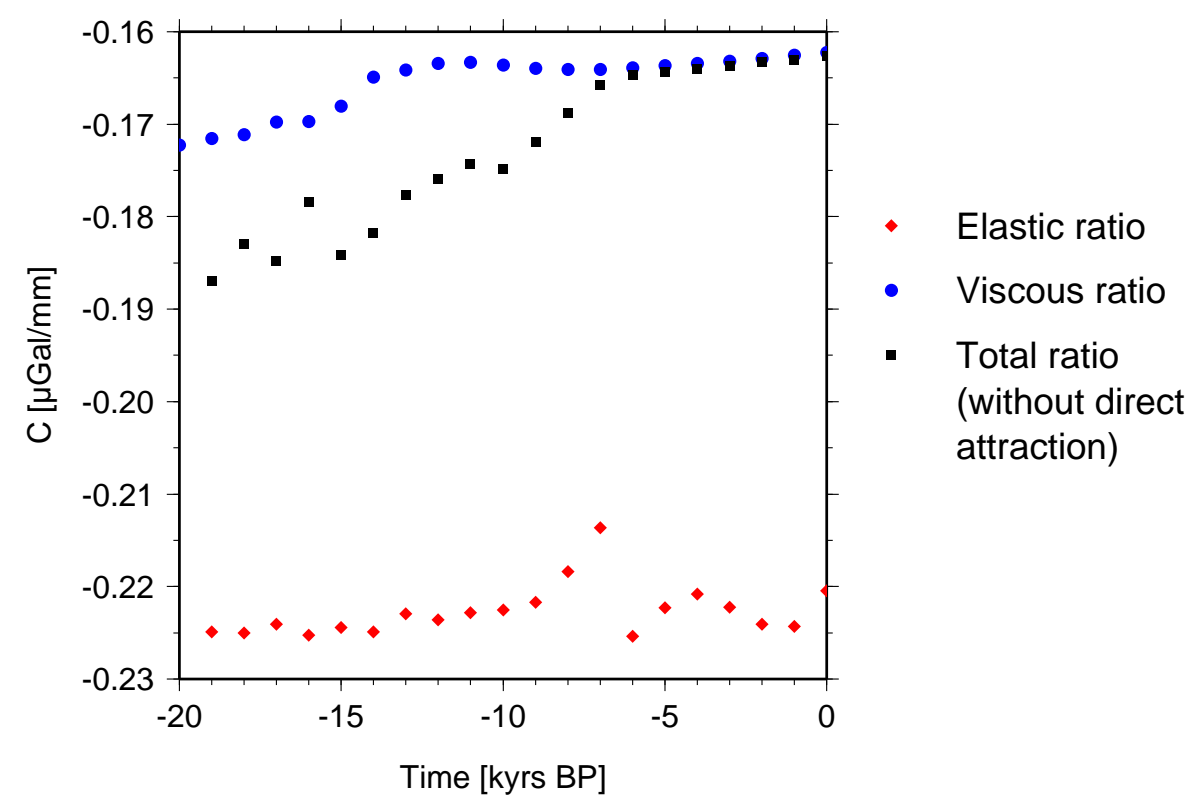

Figure 7: $C$ for Fennoscandia estimated with linear regression (Eq. 7), as a function of time. No direct attraction. Earth model 96_0.5_10 (see Table 2 ). The total signal is composed of elastic and viscous contributions, whose proportion vary with time.

Figure 7 shows that the elastic ratio is rather constant $(\sim-0.225 \mu \mathrm{Gal} / \mathrm{mm})$ throughout the whole period whereas the viscous ratio increases some, from $\sim-0.172$ to $\sim-0.163 \mu \mathrm{Gal} / \mathrm{mm}$. This increase of the viscous ratio can be explained by the diminishing ice sheet in combination with the behaviour of the Green's functions for $\dot{g}$ and $\dot{u}$ (Figure 2). Shortly after unloading, changes in gravity and uplift rates are greatest close to the location of the unloading (blue curves in Figure 2), where the absolute value of the ratio is higher (note the minus sign in front of the ratio in Figure 2). Thus, the ratio at each point in the observational grid will, after convolution over the ice (Eq. 4) at a specific time step, be dominated by the ratio from the closest loading points which contribute with a higher absolute value of the ratio. As time progresses the signal flattens out relative to the distance from the loading point (red curves in Figure 2) and the ratio is more equally composed of contributions from loading points at different distances, resulting in a lower absolute value of the ratio (less 
negative). This implies that in areas with PDIM the viscous ratio between $\dot{g}$ and $\dot{u}$ can be assumed to be lower (more negative) than the expected value in areas that have been ice free for some time.

\section{A case study of local effects}

In Section 3 we computed regional averages of the relation between predicted $\dot{g}^{e+v}$ and $\dot{u}$ and found the relation to fit a linear trend with small deviations. In these approximations the local effect of direct attraction from GIA-induced sea level changes was not included. Also, in our GIA-model we use Love numbers up to degree 180. This should be more than enough for the viscous part of the GIA signal which is dominated by long wavelengths, but is it sufficient for the elastic part?

We will now estimate the additional local effect of direct attraction and high degree elastic signal for six stations in the Nordic absolute gravity network (see Figure 8). We follow the method described in Olsson et al. (2009) which includes accurately measured heights on the stations, a very high resolution coastline $(\sim 0.5 \mathrm{~m})$ a sea level grid with very high resolution close to the station $(<0.02$ times the distance from the station) and elastic load Love numbers up to degree 10,000 (from Jentzsch, 1997) based on PREM (Dziewonski and Anderson, 1981).

The stations have been selected such that they represent locations with different sensitivities to the local signals. Visby is located on an island in the middle of the Baltic sea and is sensitive to the elastic ocean loading effect, $\dot{g}^{e}$; Smögen is located only 10 meters from the sea (and 6 meters above the sea) and is sensitive to the direct attraction from the sea water, $\dot{g}^{N}$; Kramfors and Skelleftea are located close to the uplift center where the sea level change reaches its maximum; Arjeplog is located far inland and should not be sensitive to these signals at all, and Metsähovi serves as a reference station with intermediate sensitivity. A thorough description of the stations sensitivities for different sea level induced signals can be found in Olsson et al. (2009). In Figure 8 the stations are plotted together with $\dot{u}^{e} / \dot{u}$ from the GIA-model.

With the relative sea level change $\dot{S}$ from our GIA-model (96_p5_10) we compute $\dot{u}_{\text {local }}^{e}, \dot{g}_{\text {local }}^{e}$ and $\dot{g}_{\text {local }}^{N}$ following Olsson et al. (2009). Adding $\dot{u}^{v}$ and $\dot{g}^{v}$ from our GIA-model we have

$$
\begin{aligned}
& \dot{g}_{\text {local }}=\dot{g}_{\text {local }}^{N}+\dot{g}_{\text {local }}^{e}+\dot{g}^{v} \\
& \dot{u}_{\text {local }}=\dot{u}_{\text {local }}^{e}+\dot{u}^{v}
\end{aligned}
$$

Now, replacing $\dot{g}^{e+v}$ with $\dot{g}_{\text {local }}$ and $\dot{u}$ with $\dot{u}_{\text {local }}$ in Eq. (8) we have

$$
\epsilon_{\text {local }}=\dot{g}_{\text {local }}-\left(C \cdot \dot{u}_{\text {local }}+\dot{g}_{0}\right) .
$$

which now includes the high degree elastic signal and the direct attraction from the sea. $C$ and $\dot{g}_{0}$ from Table 3, earth model 96_0.5_10. The results are presented in Table 4. Even though some of the stations are located such that 


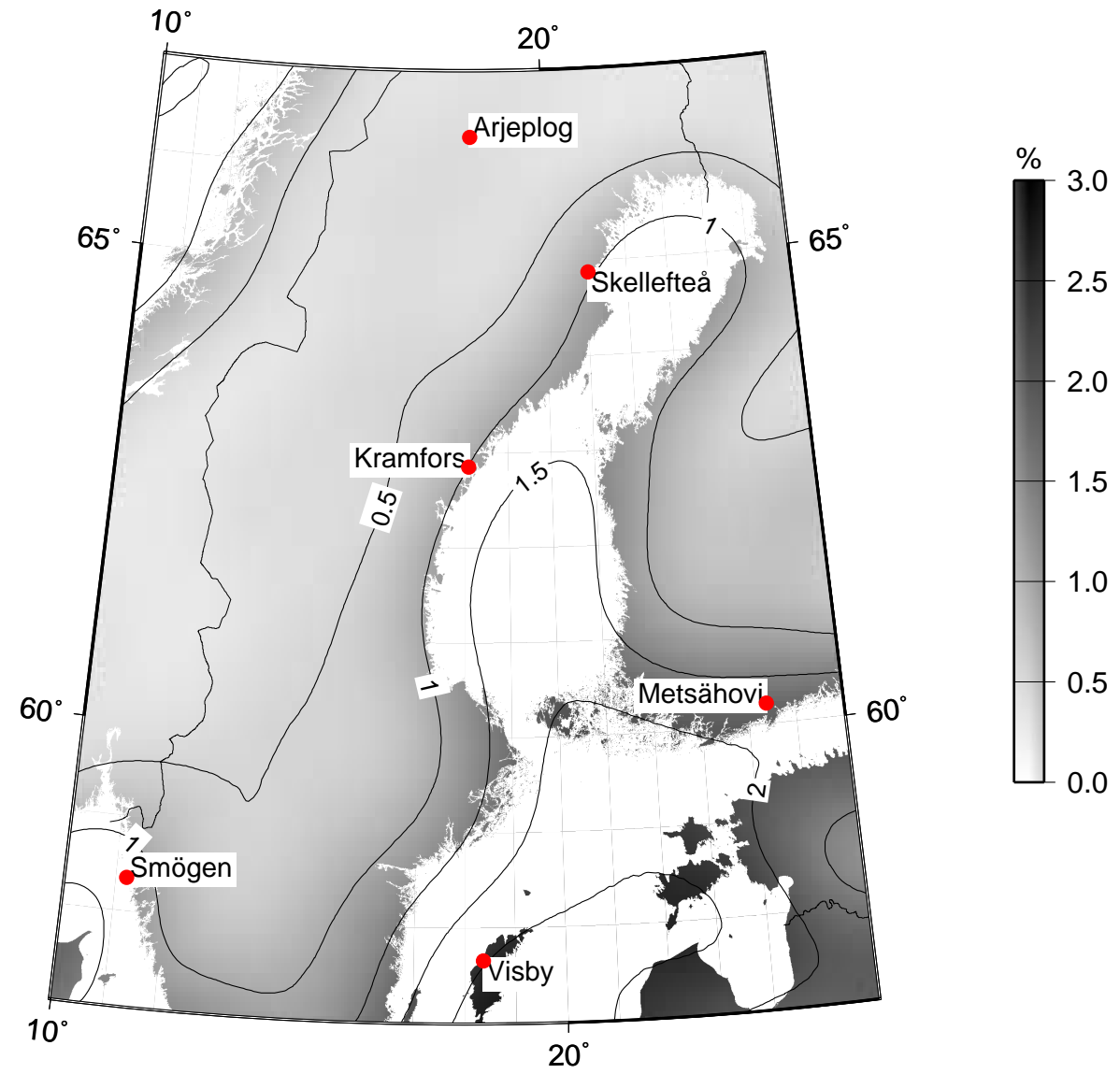

Figure 8: $\dot{u}^{e} / \dot{u}[\%]$ from the GIA modelling described in Section 2 .

Table 4: Numerical results for the case study of the local effect. $C=-0.163$ $[\mu \mathrm{Gal} / \mathrm{mm}]$ and $\dot{g}_{0}=0.030[\mu \mathrm{Gal} / \mathrm{yr}]$

\begin{tabular}{|c|c|c|c|c|}
\hline Station & $\frac{\dot{g}_{\text {local }}^{N}}{\dot{g}_{\text {local }}}[\%]$ & $\frac{\dot{g}_{\text {local }}^{e}}{\dot{g}_{\text {local }}}[\%]$ & $\frac{\dot{u}_{\text {local }}^{e}}{\dot{u}_{\text {local }}}[\%]$ & $\epsilon_{\text {local }}[\mu \mathrm{Gal} / \mathrm{yr}]$ \\
\hline Smögen & 4.4 & 1.9 & 1.4 & -0.062 \\
\hline Visby & 0.9 & 2.9 & 2.0 & -0.010 \\
\hline Arjeplog & 0.2 & 0.6 & 0.4 & -0.001 \\
\hline Kramfors & 0.9 & 1.3 & 0.9 & -0.034 \\
\hline Skellefteå & 0.4 & 1.1 & 0.8 & -0.026 \\
\hline Metsähovi & 0.5 & 1.7 & 1.1 & 0.011 \\
\hline
\end{tabular}

they should be sensitive to local effects the deviations from the linear trend are still small. Smögen is the station where the local effect has the largest impact. 
There, the direct attraction from the GIA-induced sea level variations contribute with $4.4 \%$ of total gravity change. With the local effects included the absolute value of $\epsilon$ here increases from $\sim 0.02$ to $\sim 0.06$ which is still low compared to the expected observational accuracy of $\dot{g}$ (Van Camp et al., 2005). As expected Visby, located on an island, is most sensitive to the ocean loading signal (2.9\% of the total gravity change). Since both $\dot{g}$ and $\dot{u}$ are affected by the ocean load, the impact on the ratio is small, i.e. $\epsilon$ is approximately the same as without considering the local effects, $\sim-0.01 \mu \mathrm{Gal} / \mathrm{yr}$.

\section{$5 \quad$ Summary and conclusions}

We have used the normal mode approach for a one dimensional spherically symmetric, Maxwell Earth to predict $\dot{g}$ and $\dot{u}$ in Laurentia, Fennoscandia and the British Isles. The purpose has been to study their relation in previously glaciated areas. A trustworthy relation between $\dot{g}$ and $\dot{u}$ is useful for comparing and combining the corresponding geodetic observations. Earlier studies of the relation between $\dot{g}$ and $\dot{u}$ (e.g. Wahr et al., 1995; James and Ivins, 1998; Fang and Hager, 2001; Memin et al., 2012) have shown that, given a number of approximations, the viscous part of the ratio $\dot{g} / \dot{u}$ can be considered constant enough for specific applications in Greenland and Antarctica, i.e. it is possible to use simultaneous observations of $\dot{g}$ and $\dot{u}$ to separate out the GIA-signal. We investigated the robustness of such a linear relation in previously glaciated areas. We showed numerically how the relation varies between and within the three regions. The earth model PREM was used to compute load Love numbers for six different viscosity profiles (including both compressible and incompressible rheology). The load history was defined by the ICE-5G ice model and the sea level equation was solved with time-dependent coastline geometry.

We found that the relation between $\dot{g}$ and $\dot{u}$ differs more between the three regions than between different earth models within each region. Using linear regression we estimated a linear trend

$$
\dot{g}=C \dot{u}+\dot{g}_{0},
$$

where $C \approx-0.152 \mu \mathrm{Gal} / \mathrm{mm}$ in Laurentia and $C \approx-0.163 \mu \mathrm{Gal} / \mathrm{mm}$ in Fennoscandia. The difference can be explained by the fact that the ratio between $\dot{g}$ and $\dot{u}$ depends on the dominant spherical harmonic degrees in the harmonic expansion of the load. In Laurentia the rebound signal is larger, dominated by the long wavelengths, where the absolute value of the ratio is lower. $\dot{g}_{0}$ is generally nearly, but not exactly, zero. In Great Britain and Ireland the GIA signal is close to zero which makes the ratio between $\dot{g}$ and $\dot{u}$ hard to interpret.The modelled results are compatible with observational constraints.

The simple linear approximation, common for a whole region, underestimates $\dot{g}$ close to the uplift centers and outside the uplift region, compared to the full, spatially varying model results. The maximum residuals between predictions of $\dot{g}$ using the linear approximation and full modelling are -0.17 and $-0.04 \mu \mathrm{Gal} / \mathrm{yr}$ in Laurentia and Fennoscandia, respectively. These maxima appear on the 
peripheral forebulge. Within the uplift region the residuals vary between $\sim$ \pm 0.1 and $\sim \pm 0.02 \mu \mathrm{Gal} / \mathrm{yr}$, respectively. The former value is the same as the expected observational accuracy of $\dot{g}$ after $15-25$ years of annual or semiannual AG observations (Van Camp et al., 2005).

We have also shown how the relation changes in time during the deglaciation phase. In Fennoscandia $C$ goes from $-0.19 \mu \mathrm{Gal} / \mathrm{yr}$ at LGM to $-0.16 \mu \mathrm{Gal} / \mathrm{mm}$ at present day. The major part of this variation comes from the diminishing proportion of the elastic part of the ratio (which is $\sim-0.23 \mu \mathrm{Gal} / \mathrm{mm}$ ) as the ice load gradually disappears. The viscous part of the ratio also changes during this time period, from $\sim-0.17 \mu \mathrm{Gal} / \mathrm{mm}$ at LGM to $\sim-0.16 \mu \mathrm{Gal} / \mathrm{mm}$ at presentday. This can be explained by the fact that the absolute value of the ratio between Green's functions for gravity and vertical displacement respectively decrease with the distance from the loading point (very close to the loading point the ratio is close to the Bouguer ratio discussed by e.g. Ekman and Mäkinen (1996) and James and Ivins (1998)). Shortly after the unloading the signal is concentrated close to the loading point resulting in a lower (more negative) ratio.

Local effects, such as direct attraction and short wavelength elastic deformation, from present-day GIA-induced sea level change do not significantly affect the regional averages discussed above, other than in extreme cases. If the point of observation is located closer to the sea than $\sim 10 H$ (where $H$ is the height above sea level for the point in question) then the effect from direct attraction should be considered.

In this study we have only used one ice model but we have looked at different ice sheets within this model to show how the ratio differs depending on the ice history. Using another ice model might change the numbers within each region slightly but should not affect the general conclusions.

\section{Acknowledgments}

Comments and advice from Holger Steffen have substantially improved this manuscript and are gratefully acknowledged. Maps were drawn with the GMT plotting tools by Wessel and Smith (1998). 


\section{References}

L.M. Cathles. The viscosity of the Earth's mantle. Princeton University Press, 1975.

C. de Linage, J. Hinderer, and Y. Rogister. A search for the ratio between gravity variation and vertical displacement due to a surface load. Geophysical Journal International, 171:986-994, 2007.

A.M. Dziewonski and D.L. Anderson. Preliminary reference earth model. Physics of the Earth and Planetary Interiors, 25:297-356, 1981.

M. Ekman. A consistent map of the postglacial uplift of Fennoscandia. Terra Nova, 8:158-165, 1996.

M. Ekman and J. Mäkinen. Recent postglacial rebound, gravity change and mantle flow in Fennoscandia. Geophysical Journal International, 126:229234, 1996.

M. Fang and B.H. Hager. Vertical deformation and absolute gravity. Geophysical Journal International, 146(2):539-548, 2001.

W.E. Farrell and J.A. Clark. On postglacial sea level. Geophys. J. R. astr. Soc., 46:467-667, 1976.

O. Gitlein. Absolutgravimetrische Bestimmung der Fennoskandischen Landhebung mit dem FG5-220. PhD thesis, Leibniz Universität Hannover, 2009.

T. James and E. Ivins. Predictions of antarctic crustal motions driven by present-day ice sheet evolution and by isostatic memory of the Last Glacial Maximum. Journal of Geophysical Research, 103(B3):4993-5017, 1998.

G. Jentzsch. Earth tides and ocean tidal loading. In H. Wilhelm, W. Zürn, and H.-G. Wenzel, editors, Tidal Phenomena, pages 145-172. Springer Berlin Heidelberg, 1997.

R.A. Kendall, J.X. Mitrovica, and G.A. Milne. On post-glacial sea level -II. Numerical formulation and comparative results on spherically symmetric models. Geophys. J. Int., 161:679-706, 2005.

A. Lambert, N. Courtier, and T. S. James. Long-term monitoring by absolute gravimetry: Tides to postglacial rebound. Journal of Geodynamics, 41:307$317,2006$.

K. Larson and T. van Dam. Measuring postglacial rebound with GPS and absolute gravity. Geophysical Research Letters, 27(23):3925-3928, 2000.

M. Lidberg, J.M. Johansson, H.-G. Scherneck, and J.L. Davis. An improved and extended GPS derived velocity field for the glacial isostatic adjustment in Fennoscandia. Journal of Geodesy, 81(3):213-230, 2007. 
I.M. Longman. A Green's function for determining the deformation of the earth under surface mass loads. 2. computations and numerical results. Journal of Geophysical Research, 68:485-496, 1963.

J. Mäkinen, A. Engfeldt, B.G. Harsson, H. Ruotsalainen, G. Stykowski, T. Oja, and D. Wolf. The Fennoscandian land uplift gravity lines 1966-2004. In Christopher Jekeli, Luisa Bastos, and Joana Fernandes, editors, Gravity, Geoid and Space Missions, volume 129 of International Association of Geodesy Symposia, pages 328-332. Springer Berlin Heidelberg, 2005.

S. Mazzotti, A. Lambert, J. Henton, T.S. James, and N. Courtier. Absolute gravity calibration of GPS velocitites and glacial isostatic adjustment in midcontinent North America. Geophysical Research Letters, 30:L24311, 2011.

A. Memin, J. Hinderer, and Y. Rogister. Separation of the geodetic consequences of past and present ice-mass change: Influence of topography with application to Svalbard (Norway). Pure and Applied Geophysics, 169:1357-1372, 2012.

J.X. Mitrovica and G.A. Milne. On post-glacial sea level: I. General theory. Geophys. J. Int., 154:253-267, 2003.

J.X. Mitrovica and W.R Peltier. A comparison of methods for the inversion of viscoelastic relaxation spectra. Geophys. J. Int., 108:410-414, 1992.

P.-A. Olsson, H.-G. Scherneck, and J. Ågren. Effects on gravity from non-tidal sea level variations in the Baltic Sea. Journal of Geodynamics, 48:151-156, 2009 .

P.-A. Olsson, J. Ågren, and H.-G. Scherneck. Modelling of the GIA-induced surface gravity change over Fennoscandia. Journal of Geodynamics, 61:12$22,2012$.

W.R. Peltier. The impulse response of a Maxwell Earth. Reviews of Geophysics and Space Physics, 12(4):649-669, 1974.

W.R. Peltier. Glacial-isostatic adjustment - II. The inverse problem. Geophysical Journal of the Royal Astronomical Society, 46:669-705, 1976.

W.R. Peltier. The LAGEOS constraint on deep mantle viscosity: Results from a new normal mode method for the inversion of viscoelastic relaxation spectra. Journal of Geophysical Research, 90(B11):9411-9421, 1985.

W.R. Peltier. Global glacial isostasy and the surface of the ice-age Earth: The ICE-5G (VM2) model and GRACE. Annu. Rev. Earth. Planet. Sci., 32: 111-149, 2004.

W.R. Peltier and J.T. Andrews. Glacial-isostatic adjustment - I. The forward problem. Geophysical Journal of the Royal Astronomical Society, 46(3):605646, 1976. 
B.R. Pettersen. The postglacial rebound signal of Fennoscandia observed by absolulte gravimetry, GPS and tide gauges. International Journal of Geophysics, 2011, 2011.

A. Purcell, A. Dehecq, P. Tregoning, E. K. Potter, S. C. McClusky, and K. Lambeck. Relationship between glacial isostatic adjustment and gravity perturbations observed by GRACE. Geophys. Res. Lett., 38:L18305, 2011.

H.-G. Scherneck, J.M. Johansson, G. Elgered, J.L. Davis, B. Jonsson, G. Hedling, H. Koivula, M. Ollikainen, M. Poutanen, M. Vermeer, J.X. Mitrovica, and G.A. Milne. BIFROST: Observing the three-dimensional deformation of Fennoscandia. In Jerry X. Mitrovica and Bert L. A. Vermeersen, editors, Ice Sheets, Sea Level and the Dynamic Earth, Geodynamic Series 29, pages 69-93. American Geophysical Union, 2002.

G. Spada. Solving the sea level equation, part I, theory. Samizdat Press, Golden, White River Junction, USA, 2003.

M. Van Camp, S. D. P. Williams, and O. Francis. Uncertainty of absolute gravity measurements. Journal of Geophysical Research, 110(B05406), 2005.

J. Wahr, H. DaZhong, and A. Trupin. Predictions of vertical uplift caused by changing polar ice volumes on a viscoelastic earth. Geophys. Res. Lett., 22 (8):977-980, 1995.

P. Wessel and W.H.F. Smith. New, improved version of generic mapping tools released. EOS Trans. AGU, 79(47):579, 1998.

P. Wu. Response of a Maxwell Earth to applied surface mass loads:Glacial Isostatic Adjustment. Master's thesis, Department of Physics, University of Toronto, 1978.

P. Wu and W.R. Peltier. Viscous gravitational relaxation. Geophys. J. R. astr. Soc., 70:435-485, 1982.

P. Wu and W.R. Peltier. Glacial isostatic adjustment and the free air gravity anomaly as a constraint on deep mantle viscosity. Geophys. J. R. astr. Soc., 74:377-449, 1983. 